\title{
Study of agricultural waste gasification in an air-blown bubbling fluidized bed using a CPFD model
}

\author{
Rajan Jaiswal Rajan K. Thapa Britt M. E. Moldestad \\ Department of Process, Energy and Environmental Technology, University of South-Eastern Norway, Norway, \\ \{rajan.jaiswal rajan.k.thapa, britt.moldestad\}@usn.no
}

\begin{abstract}
Gasification using a fluidized bed is a promising technology to convert agricultural residues into product gases. In this work, the syngas production potential from agricultural waste (grass pellets) is studied using a Computational Fluid Dynamic (CPFD) model. The CPFD model is developed in a simulation software Barracuda virtual reactor and validated against the experimental data. Experiments are carried out in a 20 $\mathrm{kW}$ bubbling fluidized bed gasification reactor that operates with air as fluidizing gas. Grass pellets of size $5 \mathrm{~mm}-30 \mathrm{~mm}$ in length and diameter of $5 \mathrm{~mm}$ are used as the feed.

The CPFD model considers the hydrodynamics of the gas-solid phase and reaction kinetics involved. Influence of the static bed height, bed temperature, and air to fuel ratio on the product gas composition $\left(\mathrm{CH}_{4}, \mathrm{CO}, \mathrm{CO}_{2}\right.$, and $\left.\mathrm{H}_{2}\right)$ and char conversion efficiency are investigated. Initial bed heights of $200 \mathrm{~mm}$ and 300 $\mathrm{mm}$ are used for the analysis. Biomass is fed at 2.46 $\mathrm{kg} / \mathrm{hr}$ while the air supplied is varied to obtain the air to fuel ratio at $0.4,0.6,0.8,1$, and 1.2. The result shows that the increase in bed height has a significant effect on the reactor temperature but very small effect on the product gas composition and char conversion rate. An increase in bed temperature from $600^{\circ} \mathrm{C}$ to $800^{\circ} \mathrm{C}$ improves the gasifier performance in terms of maximum product gases yield and enhanced char conversion rate. Increase in the air to fuel ratio from 0.4-1.2 reduces the $\mathrm{CH}_{4}, \mathrm{CO}$, and $\mathrm{H}_{2}$ fractions in the product gas and increases the $\mathrm{CO}_{2}$ concentration. The results obtained from the CPFD model are in good agreement with the experimental results and literature data. Thus, the CPFD model developed in this work can be utilized to optimize the gasification reactor used in a lab and industrial scale.
\end{abstract}

Keywords: grass pellets, gasification, bubblingfluidized bed, CPFD

\section{Introduction}

With the world's growing population, increase in solid wastes from households, agriculture and industries are inevitable. Strict laws and regulations are set up in the EU regions and other countries like USA and Japan to reuse and recycle the municipal solid waste (MSW).
Despite such strict measures three quarters of the MSW are still incinerated or landfilled. Converting such wastes into energy not only preserves the landfill space, but also facilitates the increasing energy demand. Thermochemical conversion technologies such as pyrolysis, combustion, and gasification enable efficient conversion of solid wastes to different energy forms such as heat and electricity. Gasification of solid wastes has several potential benefits over combustion specifically in terms of operating conditions and various reactor types suited for specific purposes. In the gasification process, the solid wastes are partially oxidized with limited amount of oxygen or steam that prevents combustion. The conversion of solid waste to product gases in a gasification process occurs in complex thermochemical routes. The first step is drying and devolatilization. The solid fuels are converted into volatile gases, char, and tar after pyrolysis and then the char is gasified with a gasifying agent (air or steam) at temperatures in the range of $600-900^{\circ} \mathrm{C}$. The process can be autothermal or allothermal, depending on the gasifying agent and the type of reactors. When using air as a gasifying medium, the process is driven autothermally. The heat required for the chemical conversion of the fuel is supplied by partial oxidation reactions. The exothermic reactions are absent when steam is used as the gasifying agent, and thus an external heat source is needed. The advantages of using steam as gasifying medium is that a synthesis gas with a higher heating value $\left(15-20 \mathrm{MJ} / \mathrm{Nm}^{3}\right)$ is produced. When using air, the caloric value of the synthesis gas is in the range of $4-8 \mathrm{MJ} / \mathrm{Nm}^{3}$. The advantage of using air as fluidizing gas is that it is cheaper, and some gas turbines available in the market enable to use lower calorific value syngas to produce electricity.

The main gas components obtained from the gasification process are methane, hydrogen, carbon monoxide and carbon dioxide. The product gases can be useful for producing biofuels and chemicals or can be used to operate gas turbines and reciprocating engines. Gasification using fluidized bed has been considered as an flexible technology that can use a wide range of fuels. Fluidized beds provide major advantages such as uniform mixing and heat transfer (Jaiswal, 2018; Jaiswal, 2019), which enables efficient conversion of carbonaceous solid into product gases. The feedstock to the gasifier has to be cheaper and more flexible in order to make the process economically sustainable. Thus, 
utilizing wastes from forest, agriculture and household as feed reduces the overall costs. Over the past few years, industrial companies and researchers around the world have assessed the benefits of converting solid waste into energy and valuable chemical products. Many researches have focused on investigating different parameters that influence the product gas composition and the gasifier efficiency.

Arena et al. performed gasification tests with different types of waste-derived fuel in a pilot scale bubbling fluidized bed using air as the gasifying agent and olivine and quartz sand as the bed material. The authors reported that gasification of polyolefin plastic wastes increases the hydrogen concentration by (20$30 \%$ ) in the syngas. In a similar study with solid recovered fuel (SRF), the authors concluded that the SRF could be gasified to obtain a syngas of valuable quality for energy applications (Arena et al., 2010).

Xiao et al. studied gasification of polypropylene plastic waste in a fluidized bed gasifier of diameter $100 \mathrm{~mm}$ and a height of $4.2 \mathrm{~m}$. The authors studied the effect of equivalence ratio, bed height and fluidization velocity on the product yield distribution, gas compositions, and gas-heating value. They found that polypropylene with air as the gasifying agent, can produce a fuel gas with a calorific value in the range of 5.2-11.4 $\mathrm{MJ} / \mathrm{Nm}^{3}$. (Xiao et al., 2007)

Alvarez et al. studied hydrogen production from gasification of a mixture of plastic and wood sawdust using steam. Adding $20 \%$ of polyethylene to the biomass (sawdust), they found that the gas yield and the hydrogen concentration increased due to the synergetic effects between increased gas components. (Alvarez et al., 2014)

Predicting performance of the fluidized bed gasifier with a simulation model is of great importance for optimum design of the reactor to achieve maximum efficiency. The CFD model can provide detail knowledge about the operational parameters to be selected. Several researches have been conducted in the fluidized bed gasification using simulation tools (Niu, 2013; Erkiaga, 2014; Shen, 2008; Chen, 2016). However, most of the studies available in literature, either lack experimental validation of the simulation model or the model does not account for the particle size distribution of the bed material and fuel particles. Particle size distribution is an important parameter that largely influences the heat and mass transfer within the bed (Grace, 1991; Beetstra, 2009) thus affect reactor performance.

In this work, a Computational Particle Fluid Dynamic (CPFD) software Barracuda VR is used. It is a commercial simulation software specially designed for the particle-fluid system. Unlike other CFD software, it is possible to define computational particles similar to the experiments with a size distribution in Barracuda. Many studies have been devoted to gain more insight into the gasification of biomass in the past using Barracuda VR (Jaiswal, 2020; Bandara, 2020; Thapa, 2016). However, limited researches are available in the field of gasification of solid wastes using a CPFD tool. In this work, the syngas production potential from agricultural waste (grass pellets) is studied using a CPFD model. The CPFD model is validated against experimental data. The CPFD model considers the hydrodynamics of the gas-solid phase and reaction kinetics involved. The influence of the static bed height, the bed temperature and the air to fuel ratio on the product gases $\left(\mathrm{CH}_{4}, \mathrm{CO}, \mathrm{CO}_{2}\right.$, and $\left.\mathrm{H}_{2}\right)$ and char conversion efficiency are investigated.

\section{Experiment}

The experimental set up used in this work consists of a $20 \mathrm{~kW}$ reactor made up of stainless steel. The reactor is $1 \mathrm{~m}$ in height and the internal diameter is $0.1 \mathrm{~m}$. Three electrical heaters are mounted on the reactor wall and heat up the reactor during operation. An air preheater is used to heat the compressed air (fluidizing gas) before it is passed into the reactor. Thermocouples and pressure sensors are placed at different heights to measure the temperature and pressure variation during the operation of the reactor. The schematic diagram of the reactor is shown in Figure 1. The biomass feedstock is supplied into the reactor by the means of two screw conveyors. A cold screw conveyer transports the biomass from the silo to the hot screw conveyer at a specified rate. The hot screw conveyor runs continuously and injects biomass into the reactor. The bed material is added to the reactor with a funnel type opening (2) attached to the wall of the reactor. A sampling line is attached at the outlet of the reactor. The gas samples are collected at certain intervals, and are analyzed in an offline gas chromatography (GC). The GC uses helium and nitrogen as the carrier gas. The hydrogen concentration is measured using nitrogen as the carrier gas, while methane, carbon monoxide, and carbon dioxide and nitrogen concentration are measured using helium as the carrier gas.

Experiments were carried out using grass pellets of $5 \mathrm{~mm}$ diameter and 5-30 $\mathrm{mm}$ in length. Sand is used as the bed material and air as the fluidizing gas. 


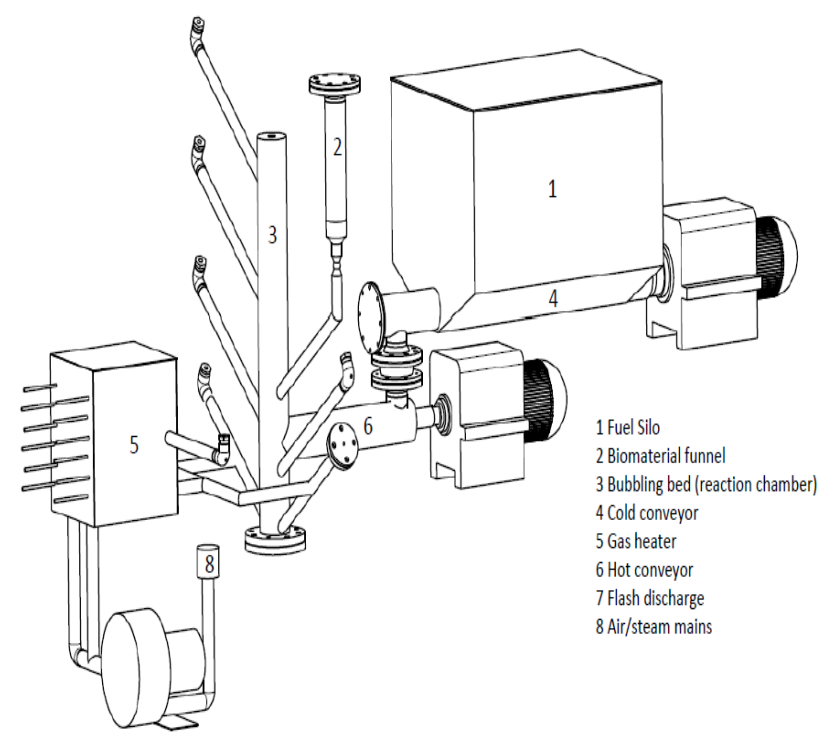

Figure 1. Experimental setup.

\section{Result and Discussion}

\subsection{CPFD model}

The developed CPFD model uses three-dimensional multiphase particle-in-cell approach for the CFD simulation of gas-particle flows. The chemistry module available in Barracuda enables to define the reactions and reaction rates involved in the gasification process. Therefore, the CPFD model simulates the thermal and chemical kinetics at the particle level providing more realistic modeling compared to other simulation software. The chemical reactions and corresponding rate kinetics used in the CPFD model are listed in Table 1.

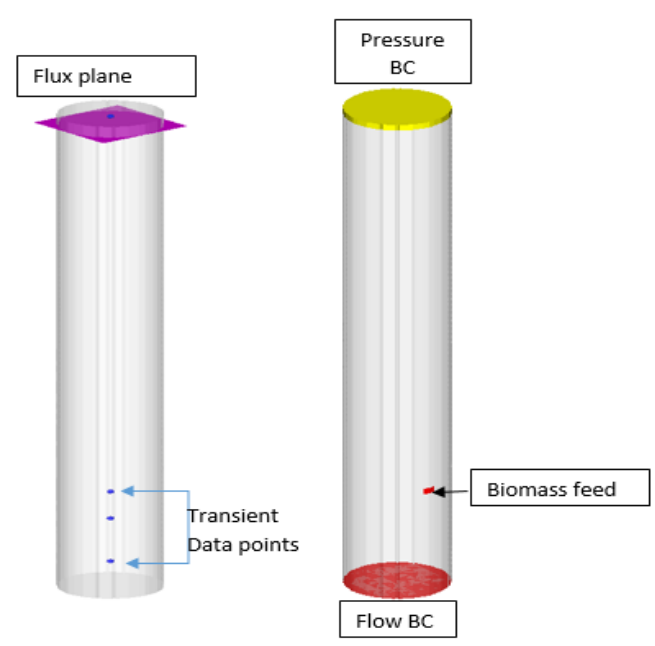

Figure 2. Transient data points, flux plane, flow and pressure boundary conditions and feed position (From left)

A CAD geometry in STL format, drawn in SolidWorks was imported, and total cells of 7128 were created using the default grid setting available in Barracuda. The properties of fuel particles (grass pellets), bed material (sand), and fluidizing gas (air) are defined as that of the experimental data. The pressure and flow boundary conditions (of air and fuel particles), transient data points, and the flux plan defined in the CPFD model are shown in Figure 2. Grass pellets (the fuel particles) of sizes $5-30 \mathrm{~cm}$ in length and $5 \mathrm{~mm}$ in diameter are used. It has a bulk density of $743 \mathrm{~kg} / \mathrm{m} 3$ and a lower heating value of $16.7 \mathrm{MJ} / \mathrm{kg}$. Sand particles of density $2600 \mathrm{~kg} / \mathrm{m} 3$ and mean diameter $345 \mu \mathrm{m}$ are used as the bed material. For the simulations, the drag model proposed by Wen Yu is used. The drag model of the particle calculates the force acting on the particle by the flow of fluid around it. The simulated product gas compositions are compared with the experimental data for validation of the model. The comparison is shown in Figure 3. The result shows that the model can predict the product gas compositions close to the experimental data.

Table 1. Chemical reactions and reaction rate (Xie, 2016; Bates, 2017; Soli, 2016).

\begin{tabular}{|c|c|}
\hline Chemical reactions & Kinetics \\
\hline $\begin{array}{l}\text { Char partial combustion } \\
\mathrm{R} 1: 2 \mathrm{C}+\mathrm{O}_{2} \leftrightarrow 2 \mathrm{CO}\end{array}$ & $\begin{array}{l}\mathrm{r}=4.34 \times 10^{10} \mathrm{~m}_{\mathrm{s}} \theta_{\mathrm{f}} \\
\exp \left(\frac{-13590}{T}\right)\left[\mathrm{O}_{2}\right]\end{array}$ \\
\hline $\begin{array}{l}\mathrm{CO} \text { oxidation } \\
\mathrm{R} 2: \mathrm{CO}+0.5 \mathrm{O}_{2} \leftrightarrow \mathrm{CO}_{2}\end{array}$ & $\begin{array}{l}\mathrm{r}=5.62 \times 10^{12} \\
\exp \left(\frac{-16000}{T}\right)[\mathrm{CO}]\left[\mathrm{O}_{2}\right]^{0.5}\end{array}$ \\
\hline $\begin{array}{l}\mathrm{H}_{2} \text { oxidation } \\
\mathrm{R} 3: \mathrm{H}_{2}+0.5 \mathrm{O}_{2} \leftrightarrow \mathrm{H}_{2} \mathrm{O}\end{array}$ & $\begin{array}{l}\mathrm{r}=5.69 \times 10^{11} \\
\exp \left(\frac{-17610}{T}\right)\left[\mathrm{H}_{2}\right]\left[\mathrm{O}_{2}\right]^{0.5}\end{array}$ \\
\hline $\begin{array}{l}\mathrm{CH}_{4} \text { oxidation } \\
\mathrm{R} 4: \mathrm{CH}_{4}+2 \mathrm{O}_{2} \leftrightarrow \mathrm{CO}_{2}+ \\
2 \mathrm{H}_{2} \mathrm{O}\end{array}$ & $\begin{array}{l}\mathrm{r}=5.0118 \times 10^{11} \mathrm{~T}^{-1} \\
\exp \left(\frac{-24357}{T}\right)\left[\mathrm{CH}_{4}\right]\left[\mathrm{O}_{2}\right]\end{array}$ \\
\hline $\begin{array}{l}\text { Water gas shift reaction } \\
\mathrm{R} 5: \mathrm{CO}+\mathrm{H}_{2} \mathrm{O} \leftrightarrow \mathrm{CO}_{2}+\mathrm{H}_{2}\end{array}$ & $\begin{array}{l}\mathrm{r}=7.68 \times 10^{10} \mathrm{~T} \\
\exp \left(\frac{-36640}{T}\right)[\mathrm{CO}]^{0.5}\left[\mathrm{H}_{2} \mathrm{O}\right]\end{array}$ \\
\hline $\begin{array}{l}\text { Methane reforming } \\
\mathrm{R} 6: \mathrm{CH}_{4}+\mathrm{H}_{2} \mathrm{O} \leftrightarrow \mathrm{CO}+ \\
3 \mathrm{H}_{2}\end{array}$ & $\begin{array}{l}\mathrm{r}=3.00 \times 105 \exp \left(\frac{-15042}{T}\right)[ \\
\left.\mathrm{CH}_{4}\right]\left[\mathrm{H}_{2} \mathrm{O}\right]\end{array}$ \\
\hline
\end{tabular}

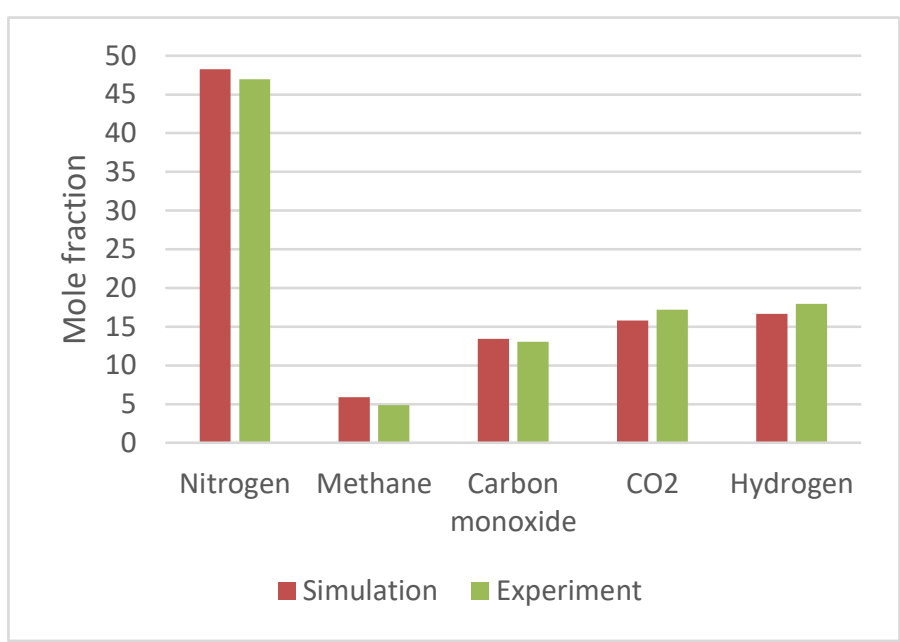

Figure 3. Product gas compositions obtained from the CPFD model and experiments (model validation). 


\subsection{Effect of static bed height}

Change in static bed height in a bubbling fluidized bed gasifier effects the bed hydrodynamic behavior (Jaiswal, 2018), the residence time of the fuel particles and the temperature of the bed. In this section, influence of the static bed height on the product gas composition and the reactor performance are discussed.

Figure 4 shows the product gas composition at static bed height of $300 \mathrm{~mm}$ and $200 \mathrm{~mm}$. For both the cases, the air to fuel $(\mathrm{A} / \mathrm{F})$ is 0.6 and the reactor is operated at $700^{\circ} \mathrm{C}$. The result shows that with increase in bed height from $200 \mathrm{~mm}$ to $300 \mathrm{~mm}$ at the same operating conditions the methane, carbon monoxide and hydrogen concentration in the product gas increases while the carbon dioxide concentration remains the same. The total heat content of the system increased with increased bed height. When the grass pellets are injected into the reactor at fluidizing conditions, the fuel particles first sink downwards in the bed and then tends to move upward due to densities differences (Jaiswal, 2019; Agu, 2019). The increase in bed height allows the fuel particles to interact with the heated bed material and the fluidizing gas for a longer time when the contact area is increased. Thus, the residence time of the fuel particles is increased, which favored the breakdown of heavy hydrocarbons, tar and char when exposed to high temperature. A similar trend is found in the experimental work performed by (Xiao et al., 2007). They tested three initial bed heights and confirmed that for an equivalence ratio maximum gas yield is obtained at a specific bed height.

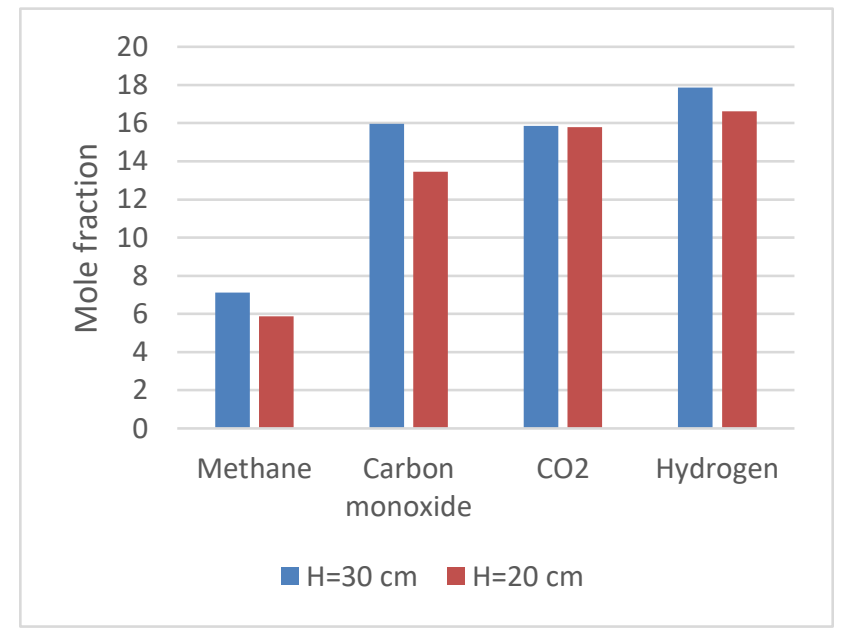

Figure 4. Change in the product gas composition with initial bed height.

\subsection{Effect of equivalence ratio}

Equivalence ratio is defined as the ratio of air to fuel supplied divided by the air to fuel ratio required for stoichiometric combustion, and is one of the important parameters in gasification of biomass with air. The equivalence ratio influences the product gas quality and quantity. Increase in equivalence ratio increases the amount of oxidant in the gasifier, and thus it influences the conversion of char and tar into the product gases depending on the temperature of the reactor.

In this work, the fuel supply (grass pellets) to the reactor is kept constant, while increasing the air flowrate and thereby increasing the equivalence ratio. Figure 5 shows the change in product gas composition at increased air to fuel ratio from 0.4 to 1.2. The concentration of methane, carbon monoxide and hydrogen is decreased and carbon dioxide concentration is increased with increase in the $\mathrm{A} / \mathrm{F}$ ratio. This is because more oxygen is added to the system that accelerates the carbon monoxide, hydrogen and methane oxidation reaction routes (R2-R4). In addition, the elevated nitrogen into the reactor with increased air to fuel ratios dilutes the product gas composition and reduces its heating value.

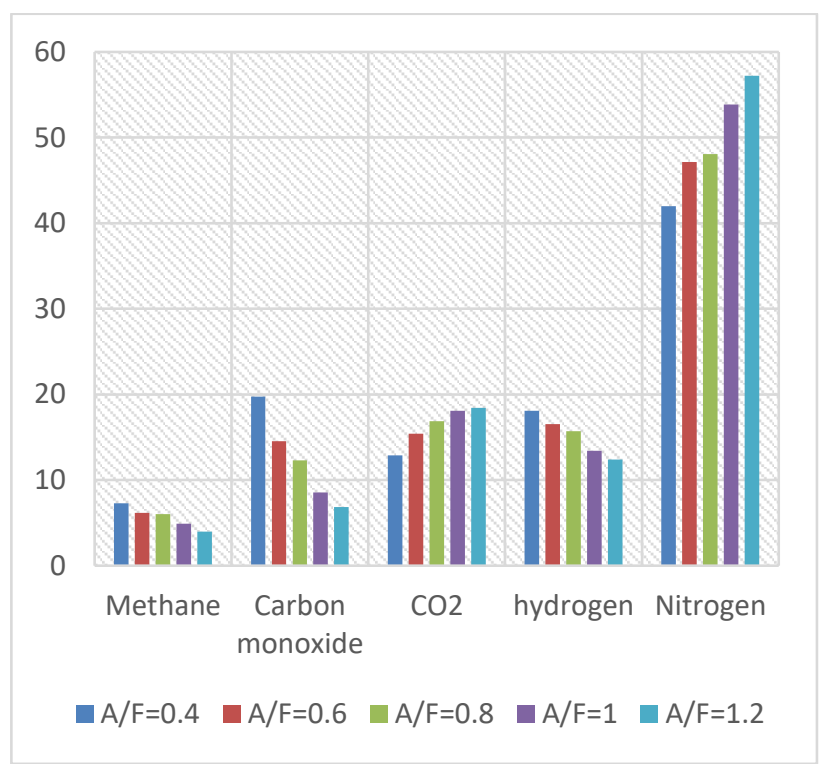

Figure 5. Product gas compositions at different air to fuel ratio.

\subsection{Effect of temperature}

Temperature in the gasifier determines the rate of chemical reactions involved in the gasification of biomass. The rate at which biomass is converted into volatile components, char, tar and finally into the product gases is influenced by the temperature in the bed and freeboard zone of the reactor. Lower temperature can end up with too much tar in the product gas and slow conversion rate of the char. While too high temperature may allow the ash to melt and stick together the bed materials, forming agglomerates and defluidization of the bubbling fluidized bed. Thus, the reactor must be operated at an optimum temperature so that the fuel particles are converted into better quality product gases with maximum gasifier efficiency. 


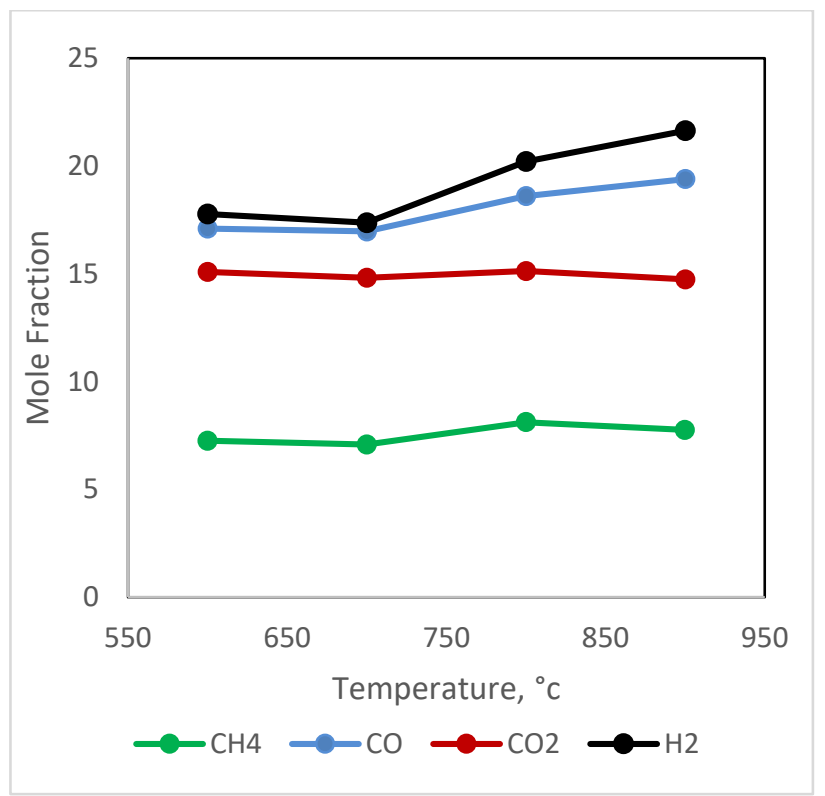

Figure 6. Product gas compositions at different reactor temperatures.

Four cases with temperatures $600^{\circ} \mathrm{C}, 700^{\circ} \mathrm{C}, 800^{\circ} \mathrm{C}$, and $900^{\circ} \mathrm{C}$ are tested at air flowrate of $2 \mathrm{~kg} / \mathrm{hr}$ and grass pellets feed rate at $2.46 \mathrm{~kg} / \mathrm{hr}$. The initial bed height is $200 \mathrm{~mm}$ for all the cases. Figure 6 depicts the product gas composition obtained at different reactor temperatures. With change in temperature from $600^{\circ} \mathrm{C}$ to $900^{\circ} \mathrm{C}$, the concentration of hydrogen and carbon monoxide increased significantly and the methane fraction increased slightly. The reason is that the reaction routes (shown in Table 1), char partial oxidation (R1), water-gas-shift reaction (R5) and methane reforming (R6), are enhanced with the increase in temperature. The fraction of hydrogen and carbon monoxide increased from $17 \%$ to $21 \%$ and $19 \%$ respectively. Increase in quantity of higher calorific value gases enhance the lower heating value (LHV) of the product gas. The LHV and cold gas efficiency (CGE) of the product gas with change in temperature is shown in Figure 7. LHV of the product gas increases from $6.8 \mathrm{MJ} / \mathrm{Nm}^{3}$ to $7.5 \mathrm{MJ} / \mathrm{Nm}^{3}$. Since the CGE of the product gas is directly related to LHV of the gas (shown in equation 1), the CGE of product gas increases with increase in LHV of the gas. The CGE of the product gas increased from $58 \%$ to $66.6 \%$.

$$
\begin{aligned}
& C G E(\%)= \\
& \text { LHV of the syngas } * \text { syngas flow rate } * 100 \\
& \text { LHV of the fed grass pellets } * \text { grass pellets } \\
& \text { feed rate } \\
& L H V\left(\frac{M J}{N m^{3}}\right)=\frac{C O * 126.36+H_{2} * 107.98+C_{4} * 358.18}{1000}
\end{aligned}
$$

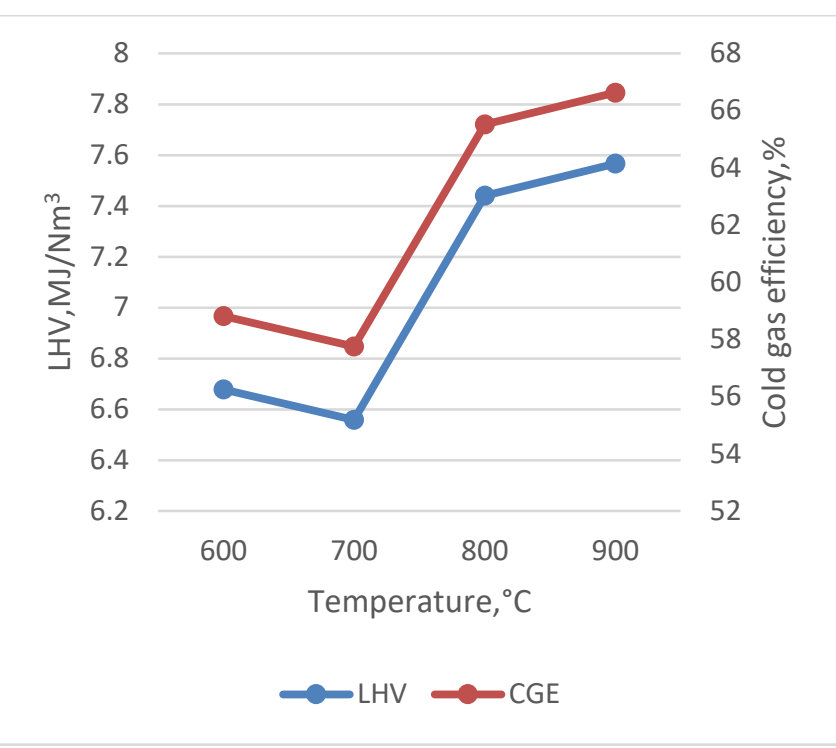

Figure 7. Lower heating value and cold gas efficiency of the product gas at different reactor temperatures.

\section{Conclusion}

The main objective of this work was to investigate the syngas production potential from gasification of agricultural wastes (grass pellets) using a commercial CPFD simulation software Barracuda VR. Experimental data were used to validate the CPFD model. Experiments were conducted on a $20 \mathrm{~kW}$ bubbling fluidized bed gasifier with air as a fluidizing gas and sand as the bed material. Grass pellets were fed to the reactor at $2.46 \mathrm{~kg} / \mathrm{hr}$. The samples were collected and measured in an offline GC. The product gas compositions obtained from the simulation results and the experimental data were compared for the model validation.

The influence of initial bed height, temperature and air to fuel ratio on the product gas compositions and gasifier performance were investigated. The result shows that with increase in initial bed height from 200 $\mathrm{mm}$ to $300 \mathrm{~mm}$ there is a slight increment in the product gas yield and a significant increment in the reactor temperature. Different air to fuel ratios, 0.4, 0.6, 0.8, 1 , 1.2 , were simulated and the result shows that the quality of the product gas decreases with increase in the air to fuel ratio from 0.4 to 1.2 . More carbon dioxide and nitrogen are released in the product gas at the higher value of air to fuel ratio. Decrease in the $\mathrm{CH}_{4}, \mathrm{CO}$, and $\mathrm{H}_{2}$ fractions in the product gas reduce the heating value of the gas. Increase in temperature from $600^{\circ} \mathrm{C}$ to $900^{\circ} \mathrm{C}$ enhances the product gas quality. The fraction of hydrogen and carbon monoxide in the product gas increased from $17 \%$ to $21 \%$ and $19 \%$ respectively. Similarly, the CGE of the product gas increased from $58 \%$ to $66.6 \%$ with increase in reactor temperature.

The CPFD model developed in this work can predict results that are good in agreement with the experimental 
data. Therefore, the model can be utilized to optimize the gasification reactor.

\section{References}

C. E. Agu, L.-A. Tokheim, C. Pfeifer, and B. M. Moldestad. Behaviour of biomass particles in a bubbling fluidized bed: A comparison between wood pellets and wood chips, Chemical Engineering Journal, 363: 84-98, 2019. https://doi.org/10.1016/j.cej.2019.01.120

U. Arena, L. Zaccariello, and M. L. Mastellone. Fluidized bed gasification of waste-derived fuels, Waste Management, 30(7): 1212-1219, 2010/07/01/2010.

https://doi.org/10.1016/j.wasman.2010.01.038

U. Arena and F. Di Gregorio. Gasification of a solid recovered fuel in a pilot scale fluidized bed reactor, Fuel, 117: 528536, 2014. https://doi.org/10.1016/j.fuel.2013.09.044

J. Alvarez. Hydrogen production from biomass and plastic mixtures by pyrolysis-gasification, International Journal of Hydrogen Energy, 39(21): 10883-10891, 2014. https://doi.org/10.1016/j.ijhydene.2014.04.189

R. Beetstra, J. Nijenhuis, N. Ellis, and J. R. van Ommen. The influence of the particle size distribution on fluidized bed hydrodynamics using high-throughput experimentation, AIChE journal, 55(8): 2013-2023, 2009. https://doi.org/10.1002/aic.11790

J. C. Bandara, C. Jayarathna, R. Thapa, H. K. Nielsen, B. M. Moldestad, and M. S. Eikeland. Loop seals in circulating fluidized beds-Review and parametric studies using CPFD simulation, Chemical Engineering Science, 115917, 2020. https://doi.org/10.1016/j.ces.2020.115917

R. B. Bates et al., Steam-air blown bubbling fluidized bed biomass gasification (BFBBG): Multi-scale models and experimental validation, AIChE Journal, 63(5):1543-1565, 2017. https://doi.org/10.1002/aic.15666

J. Chen et al., Analysis of biomass gasification in bubbling fluidized bed with two-fluid model, Journal of Renewable and Sustainable Energy, 8(6): 063105, 2016. https://doi.org/10.1063/1.4967717

A. Erkiaga, G. Lopez, M. Amutio, J. Bilbao, and M. Olazar. Influence of operating conditions on the steam gasification of biomass in a conical spouted bed reactor, Chemical engineering journal, 237: 259-267, 2014. https://doi.org/10.1016/j.cej.2013.10.018

J. Grace and G. Sun. Influence of particle size distribution on the performance of fluidized bed reactors, The Canadian Journal of Chemical Engineering, 69(5): 1126-1134, 1991. https://doi.org/10.1002/cjce.5450690512

R. Jaiswal, C. E. Agu, R. K. Thapa, and B. M. E. Moldestad. Study of fluidized bed regimes using Computational Particle Fluid Dynamics, Proceedings of the 59th
Conference on Simulation and Modelling, 2018. DOI:10.3384/ecp18153271

R. Jaiswal, N. C. I. Furuvik, R. K. Thapa, and B. M. E. Moldestad. Investigation of the segregation and mixing behavior of biomass in a bubbling fluidized bed reactor using a CPFD model, Proceedings of the 60th SIMS Conference on Simulation and Modelling, 2019.

https://doi.org/10.3384/ecp20170164

R. Jaiswal, N. C. Furuvik, R. K. Thapa, and B. M. Moldestad. Method of identifying an operating regime in a bubbling fluidized bed gasification reactor, International Journal of Energy Production and Management, 5(1): 24-34, 2020. Doi: 10.2495/EQ-V5-N1-24-34

M. Niu, Y. Huang, B. Jin, and X. Wang. Simulation of Syngas Production from Municipal Solid Waste Gasification in a Bubbling Fluidized Bed Using Aspen Plus, Industrial \& Engineering Chemistry Research, 52 (42): 14768-14775, 2013/10/23 2013. https://doi.org/10.1021/ie400026b

L. Shen, Y. Gao, and J. Xiao. Simulation of hydrogen production from biomass gasification in interconnected fluidized beds, Biomass and bioenergy, 32(2): 120-127, 2008.

https://doi.org/10.1016/j.biombioe.2007.08.002

K.-A. Solli, R. K. Thapa, and B. M. E. Moldestad. Screening of Kinetic Rate Equations for Gasification Simulation Models, The 57th SIMS Conference on Simulation and Modelling SIMS 2016, Linköping University Electronic Press, 142: 105-112. DOI: 10.3384/ecp17142105

R. Xiao, B. Jin, H. Zhou, Z. Zhong, and M. Zhang. Air gasification of polypropylene plastic waste in fluidized bed gasifier, Energy Conversion and Management, 48 (3): 778786, 2007.

https://doi.org/10.1016/j.enconman.2006.09.004

J. Xie, W. Zhong, B. Jin, Y. Shao, and Y. Huang. EulerianLagrangian method for three-dimensional simulation of fluidized bed coal gasification, Advanced Powder Technology, 24(1): 382-392, 2013. https://doi.org/10.1016/j.apt.2012.09.001 